\title{
Considerações sobre cozinha patrimonial e turismo
}

\section{Considerations about the patrimonial cuisine and tourism}

\author{
Ewerton Reubens Coelho Costa ${ }^{1}$ \\ ewertonreubens@hotmail.com \\ Maria Socorro Figueiredo dos Santos ${ }^{2}$ \\ socorrofsantos@bol.com.br
}

\section{Resumo}

Este artigo tem como objetivo buscar maior entendimento sobre as cozinhas patrimoniais e sua relação com a atividade turística. Trata-se de um estudo exploratório baseado em revisão bibliográfica. Dentre os achados da pesquisa, conclui-se que as cozinhas patrimoniais abrangem saberes e fazeres ligados à gastronomia de uma sociedade; o que é patrimonializado não são ingredientes ou receitas, mas ofícios e produções cujos saberes e fazeres são reconhecidos pelas sociedades como parte de sua cultura, de sua identidade. E que o turismo é uma excelente vitrine para explorar as cozinhas como atrativo turístico que permite aos visitantes experienciar a cultura alimentar de um lugar.

Palavras-chave: Cozinha Patrimonial; Turismo; Cultura.

\begin{abstract}
This paper aims to contribute to understand the patrimonial cuisines and its relation to tourism. It is an exploratory study based on literature review. Among the findings of the research, it is concluded that the patrimonial cuisines include knowledge and practices related to gastronomy of a society; its heritage is not limited to ingredients or recipes, but crafts and productions whose knowledge and practices are recognized by societies as part of their culture, their identity. And that tourism is an excellent showcase for exploring the cuisines as a tourist attraction that allows visitors to experience the food culture of a place.
\end{abstract}

Keywords: Patrimonial Cuisines; Tourism; Culture.

1 Mestre em Gestão de Negócios Turísticos pela Universidade Estadual do Ceará (UECE), e graduado em Gestão de Turismo pelo Instituto Federal de Educação, Ciência e Tecnologia do Ceará (IFCE). É também formador de Gestores das Políticas Públicas do Turismo pelo Ministério de Turismo (MTur) e Universidade Federal de Santa Catarina (UFSC).

2 Doutora em Geografia pela Unesp, mestre em Gestão de Negócios Turísticos e especialista em Metodologia do Ensino, ambos pela UECE, e graduada em Economia Doméstica pela Universidade Federal do Ceará (UFC). É professora efetiva do IFCE, onde também integra a Comissão de Ética em Pesquisa. 
A cultura gastronômica constitui novo paradigma na efervescência patrimonial (QUINTERO MÓRON, 2005) desde que a Organização das Nações Unidas para a Educação, a Ciência e a Cultura (Unesco) introduziu a Convenção para Salvaguarda do Patrimônio Imaterial, em 2003, e, a partir de então, passou-se a relacionar as cozinhas com questões de identidade, memória e cultura, incluindo-as como patrimônio gastronômico - classificado como patrimônio imaterial - das sociedades.

As implicações socioculturais da construção do patrimônio material são igualmente aplicáveis à construção do patrimônio gastronômico, ou patrimônio alimentar, que apesar de se configurar como patrimônio intangível, inclui ambos os elementos - materiais e imateriais.

Entende-se como patrimônio gastronômico o conjunto de elementos tangíveis e intangíveis de culturas alimentares consideradas patrimônio compartilhado, ou bem comum, para a coletividade. O patrimônio gastronômico de determinado coletivo é uma seleção de parte de sua "cultura alimentar", a que se atribui a "tradicionalidade".

Este tipo de patrimônio é constituído por produtos agrícolas, saberes e fazeres associados a estes produtos, e formas de produção e distribuição de alimentos. Pode-se também incluir: as formas de sociabilidade à mesa, a simbologia alimentar e os objetos de mesa (BESSIÈRE \& TIBÉRIO, 2010). Neste contexto, compreende-se a existência das Cozinhas Patrimoniais, que detêm diversas produções patrimonializadas.

Assim, a cultura gastronômica, considerada "ativo global" e "recurso local" (ALVAREZ, 2008), torna-se catalizadora de projetos que geram desenvolvimento na atividade turística, integrando comida e cultura, explorando as cozinhas patrimoniais para criar novas possibilidades de atrativos e competitividade para destinos turísticos.

Para compreender o discurso patrimonial em torno das cozinhas, faz-se fundamental não só o entendimento do que está sendo patrimonializado, mas compreender as possibilidades de uso desse patrimônio, sobretudo na atividade turística.

Este artigo é um estudo exploratório com base na revisão da literatura. Tem como objetivo identificar as características de uma cozinha patrimonial e sua relação com o turismo. Para tanto, parte das seguintes questões: as cozinhas podem ser patrimonializadas? Como ocorre o uso das cozinhas patrimoniais na atividade turística? As respostas para estes questionamentos serão dadas a seguir.

\section{Breves considerações sobre alimentos como patrimônio}

Partindo do pensamento de Fischler (1979), que afirma que o homem é um onívoro que se alimenta de carne, vegetais e de imaginário, e que a alimentação conduz a biologia, mas, evidentemente, não se reduz a ela, compreende-se a alimentação humana como ato sociocultural ligado a uma rede de representações em que a escolha e o consumo de alimentos põem em jogo uma série de fatores de ordem histórica, cultural, social, ecológica e econômica. A comida torna-se, então, uma realização social altamente condensada de representações coletivas e mobiliza emoções (APPADURAI, 1981).

Para Nurayan (1995), o alimento ajuda na compreensão de identidades coletivas e pessoais. Assim, comer é ato social complexo que põe em cena, além do consumo de material simbólico diferenciado e diferenciador, movimentos de produção e de consumo de alimentos; processos culturais e sociais que sustentam identidades e relações de poder. Deste modo, existe a possibilidade de patrimonializar as cozinhas.

Inicialmente, o patrimônio esteve concentrado em bens materiais, sobretudo no patrimônio arquitetônico. Porém, a partir da década de 1970 passa a abranger o patrimônio cultural, com um conceito mais amplificado e intangível, que levou sociedades a conhecerem o que se entende como Patrimônio Cultural Imaterial.

O Patrimônio Cultural Imaterial, transmitido de geração em geração, é constantemente recriado pelas comunidades e grupos em função de seu ambiente, de sua interação com a natureza e de sua história, gerando um sentimento de identidade e continuidade, contribuindo assim para promover o respeito à diversidade cultural e à criatividade humana (UNESCO, 2003).

Entende-se por 'Patrimônio Cultural Imaterial' as práticas, representações, expressões, conhecimentos e 
técnicas - junto com os instrumentos, objetos, artefatos e lugares que lhes são associados - que as comunidades, os grupos e, em alguns casos, os indivíduos reconhecem como parte integrante de seu patrimônio cultural.

Partindo da existência de mapeamentos de instituições e atores sociais a respeito de saberes e fazeres, de representações rituais à mesa com conteúdo material e simbólico, Pierre Nora (1984) afirma que o patrimônio, nas últimas décadas, passou por uma metamorfose no entendimento conceitual: de herança ancorada em uma sociedade a patrimônio repleto de simbolismo e identidade; de patrimônio herdado a patrimônio reivindicado; de patrimônio visível a patrimônio invisível; de patrimônio material a patrimônio imaterial; de patrimônio estatal a patrimônio social, étnico e comunitário. Isto é, passou-se de um regime de patrimônio restrito para generalizado, em que categorias somam a noção de cultura, memória e identidade.

Compreender o patrimônio enquanto construção social permite conhecer os entraves e conflitos no processo de seleção e definição de políticas de salvaguarda e preservação do patrimônio. Como explica Arantes (1984): espaços, práticas e bens diversos são removidos do fluxo da vida cotidiana, se reúnem, ressignificam e recontextualizam e participam da dinâmica específica da dimensão da cultura que criam e recriam os organismos públicos de preservação. Uma vez que integram o patrimônio, adquirem certificado de naturalização e o processo de seleção e interpretação ficam ocultos. Arantes ainda apresenta a seleção e preservação do patrimônio como atividade produtiva, que gera valores econômicos, simbologias construtivas de memória, territorialidade e identidade nacional, e outras identidades mais especificas e de valor político, por remeter ao aspecto de hegemonia e aos direitos dos cidadãos.

\begin{abstract}
Os alimentos convertidos em patrimônio não esgotam tudo o que a cultura alimentar é, muitas vezes não se apresentam de maneira fidedigna uma parte dela [...] este processo de seleção, fragmentação, descontextualização, modificação de usos e funções, adaptação e reinterpretação é explicada pelo papel a ser atribuído a este patrimônio, pelo espaço que vai ser ocupado e pelos interesses a que eles servem (ESPEITX, 2004, p. 196).
\end{abstract}

A valoração dessas dimensões inter-relacionam-se no processo de apropriação social de bens. Com isso, permite-se analisar políticas de patrimonialização, entender tradicionalismos e estabelecer críticas sobre a valorização do patrimônio (MATECÓN, 1991), seja ele tangível ou intangível, do presente e do passado, incluindo, sem dúvidas, a comida.

\title{
Cozinhas e patrimônio
}

O termo culinária deriva de cozinha que, por sua vez, vem do francês cuisine, e indica o espaço físico onde se prepara alimentos. Do termo designa ainda o caráter étnico de uma cozinha. Por conta disso, Barceló (2007) destaca que deve ser feita referência à "cozinha regional”, ao invés de cozinha nacional, pois é nela que se encontra o consumo mais frequente dos preparados comuns em sociedades, em que as características são fáceis de serem encontradas, assim como os modos de preparo, as técnicas e os sabores.

Nesta linha de pensamento, Pérez San Vicente (2002, p. 82), apresenta considerações sobre gastronomia e cozinhas regionais, de onde se apreende que: cada cozinha tem uma essência particular, sendo composta por um conjunto de regras que a caracterizam e a identificam, as quais não devem ser transgredidas para que não se perca sua identidade; toda cozinha se origina em um lugar geográfico especifico - que determina seus espaços, seu povo, seus produtos e insumos; e uma cozinha é diferenciada por seus conjuntos de preparações (pratos). Pérez San Vicente (2002, p. 82-83) ainda apresenta itens base que toda cozinha deve seguir:

- Ter surgido no território (referência ao lugar), que estabelece e determina seu espaço;

- Ter desenvolvido utensílios próprios;

- Ter produzido seus próprios insumos e materiais;

- Ter inventado métodos e formas de cozinhas;

- Ter uma gama de preparações que abranja todos os sabores - do amargo ao doce, do salgado ao amargo, do áspero ao suave;

- Ser concebida para integrar a totalidade dos passos de uma refeição, desde a en- 
Dossiê

trada, passando pelos caldos, pelas sopas, os guisados até as sobremesas;

- Ter estabelecido costumes, etiquetas, sistemas e horários - o que implica em, pelo menos, terem sido desenvolvidos ao longo de três gerações, ou seja, a cerca de 150 anos;

- Ter seu universo constituído pelas cozinhas regionais;

- Ser capaz de usar o conhecimento de outras cozinhas para incorporá-los, sem alterar sua essência;

- Ter criado preparações culinárias (pratos) que a identificam internacionalmente.

- Uma cozinha se torna gastronomia quando cria suas próprias bebidas, com seus insumos e métodos, sua panificação, biscoitaria, confeitaria, doces e bolos e técnicas de conservação;

- Que em sua honra se tenha originado uma literatura e poesia, e que também existam provérbios;

Já Farb e Armelagos (1985) apresentam cozinha como estrutura que inclui quatro elementos fundamentais. São eles:

- Número de alimentos limitados, selecionados dentre aqueles oferecidos pelo meio, por capacidade de acesso e uso de energia;

- O modo característico de preparar alimentos - cortado, grelhado, assado, cozido, frito, etc.;

- O princípio ou princípios de condimentação tradicional do alimento, base de cada conjunto social;

- E a adoção de um conjunto de regras relativas ao status simbólico de alimentos, como o número de refeições diárias e especificação para que os alimentos sejam consumidos individualmente ou em grupos. As cozinhas, assim, consideradas têm várias dimensões, tais como: étnica, nacional e/ou regional. Ao identificar expressões alimentares pode-se, ao mesmo tempo, indicar uma identidade gastronômica e a origem territorial de uma pessoa ou grupo.

Assim, constata-se a possibilidade de construir e interpretar o imaginário alimentar, tecendo reinterpretações desses significados e construções. Para DaMatta (1987), o ato de comer apresenta estados emocionais e identidades sociais. $\mathrm{O}$ eu, na cozinha, significa dizer que, se existe acesso ou restrição a ingredientes, as receitas podem ganhar versões diferentes de um mesmo prato. Contudo, o que se deseja é a permanência do significado, da posição da estrutura alimentar, do valor semântico do que é preparado. Como explica González Turmo (1999), a patrimonialização é uma ponte que traça uma linha de continuidade entre o passado e o futuro, entre o conhecido e o desconhecido; é simbolização.

Partindo dessas premissas, percebe-se a relação das cozinhas com o patrimônio cultural imaterial. Principalmente quando se entende por "patrimônio cultural imaterial" as práticas, representações, expressões, conhecimentos e técnicas - junto com os instrumentos, objetos, artefatos e espaços culturais que lhe são inerentes - que as comunidades, os grupos e, em alguns casos, os indivíduos reconhecem como parte integrante de seu patrimônio cultural. Este patrimônio cultural imaterial, que se transmite de geração em geração, é constantemente recriado pelas comunidades e grupos em função de seu ambiente, de sua interação com a natureza e sua história, com um sentimento de identidade e continuidade, promovendo o respeito pela diversidade cultural e criatividade humana (UNESCO, 2003). Neste caso, o patrimônio imaterial se manifesta pelos usos sociais, rituais e atos festivos que se compreende como tradições culinárias.

Agrega-se a isso o conceito de patrimônio gastronômico apresentado em Barceló (2007), que considera a existência de bens patrimoniais alimentares destinados a satisfazer necessidades distintas. Deste modo, o patrimônio alimentar se expande, uma vez que implica uma cultura da alimentação que inclui sistemas agroalimentares, produtos locais, cozinhas regionais ou tradicionais, gastronomia, produção de alimentos, técnicas agrícolas e culinárias, dietas, valorização e alimentos tradicionais, microambientes - com sistemas e sensibilidades.

Freyre (1967, p. 72), em Manifesto Regionalista, adverte que "uma cozinha em crise significa uma civilização inteira em perigo" - o perigo de descaracterizar-se. Uma "cozinha é um reativo de rara sensibilidade 
para avaliar a cultura de uma população, é um conjunto de signos e símbolos que ao serem interpretados dão compreensão à história civilizatória de um povo" (LIMA, 2005, p. 14).

Logo, a alimentação se insere no contexto simbólico de características culturais, sociais e econômicas que traz desenvolvimento e aprimoramento de saberes e fazeres a partir de relações humanas, e determinando identidades próprias (LODY, 2008). O que vai de acordo com as ideias de Montanari (2008, p. 183), que afirma que, "assim como a língua falada, o sistema alimentar contém e transporta a cultura de quem a pratica, é depositário das tradições e da identidade de um grupo". Isso torna possível entender a construção de cozinhas regionais a partir da coletividade absorvida culturalmente, de forma codificada, mas reconhecida.

A partir de 1996 a Unesco, preocupada com preservação do patrimônio, lança ações para desenvolver o turismo cultural no Caribe e América Latina. Dentre ações variadas, está a urgência de resgatar e desenvolver reflexões a respeito da culinária regional. Isso coloca as culinárias como recurso e diferencial competitivo de lugares no âmbito internacional. O documento base elaborado pela Unesco, em 2003, coloca saberes e fazeres, incluindo receitas, como bens culturais e exige reconhecimento de políticas culturais que enxerguem a alimentação e a gastronomia como elementos culturais importantes (FARB \& AMELAGOS, 1985).

Constata-se, então, a alimentação como linguagem que trata materialmente de dimensões simbólicas e sociais, e que coloca as expressões alimentares, como as cozinhas, enquanto formas de comunicação.

Alimentos que possuem poucas ligações culturais são mais fáceis de serem substituídos e, portanto, têm menores potencialidades de se configurar como patrimônio. Como patrimônio cultural, a gastronomia é:

Certamente muito mais do que simples arte culinária. Assume-se também como um importante veículo da cultura popular, ao mesmo tempo em que possibilita percepção acerca da forma como vivem os habitantes de cada região, numa dada época (ANTONINI, 2003, p. 35).

Desta maneira, a patrimonialização de cozinhas ou de produtos gastronômicos diz respeito ao conhecimento empregado para a confecção desses produtos, ou seja, o que de fato é patrimonializado não são os alimentos, mas os saberes e fazeres para a produção deles; e ainda são preservados os ofícios, isto é, quem domina estes saberes e fazeres nas sociedades.

A mundialização da cultura destaca as consequências da modernidade sobre hábitos alimentares, como o hábito de comer fora e o fast-food - costumes recentes e que se impõem no mundo moderno -, e os compreende como reflexo da modernidade na alimentação (CARVALHO, 2014; GIORGI, 2015). Fato que fragmenta a "instituição da refeição" e faz levantar a questão de como se patrimonializar a gastronomia da modernidade.

Para Turmo (1999) a gastronomia representa um elemento de diferenciação cultural de grande importância para um destino turístico. Com ela se pode aumentar a oferta turística agregando valores; além de ser importante veículo de cultura popular, que se transmite e se reconhece pelos saberes e fazeres de uma sociedade em determinado período.

Assim, pode-se dizer que as comidas típicas de uma região estão intimamente ligadas à cultura do lugar (CORNER, 2003), e por isso devem ser preservadas, valorizadas e transmitidas paras novas gerações como parte do patrimônio do lugar onde se originam. Assim, na medida em que o homem se alimenta valorizando determinados ingredientes e seguindo hábitos alimentares da sociedade a qual pertence, constitui-se uma interação não só com o instinto de sobrevivência, mas com os valores, com a história, com a geografia e com o passado.

Indiscutivelmente, a gastronomia enquanto produção sociocultural permite interações com várias áreas do conhecimento humano. No entanto, reconhecer a herança culinária é o primeiro passo para explorá-la como recurso que gera desenvolvimento e competitividade.

A existência de cozinhas diferenciadas, além dos atributos que lhe conferem um diferencial, representa a expressão cultural de uma sociedade, a identidade de um povo. Por este motivo, Barros (2000; 2008) e Pilcher (2001) destacam que as cozinhas requerem reconhecimento, investigação, preservação e impulso especial. Principalmente quando se considera a sobrevivência cultural e o desenvolvimento econômico.

Considerando que a cozinha patrimonial é constituída por expressões que identificam a si e o grupo 
ao qual se pertence, e dentre essas expressões se tem o material e o imaterial - em que se percebe a tradição e se definem gostos - entende-se que, neste caso, o gosto não é só um indicador de classe, mas uma prática de classificação (BOURDIEU, 1988).

Levando em conta que a construção de padrões e tradições gastronômicas é feita a partir da constante reinterpretação de significados dos alimentos, Gonzalez Turmo (1999) sugere formas para se avaliar o processo de assimilação da culinária, tanto no aspecto cultural de novos alimentos - que podem substituir outros ou apenas serem incorporados a uma preparação -, quanto para reinterpretar tradições por meio de sua descontextualização.

A existência de uma "novidade" na estrutura alimentar implica na existência de um novo significado para o ingrediente e para a cultura. Com isso, percebe-se a inclusão de preparações que deixaram de ser corriqueiras e tornaram-se rituais, presentes em momentos repletos de significados e simbologia - como as comidas de Natal, Semana Santa, comidas de festas -, e, em outros casos, ocorre o inverso, quando um prato especial se torna cotidiano - como o sushi japonês, as massas italianas ou os doces árabes que acabam se tornando comuns devido às redes de restauração que têm se massificado.

Não se quer dizer com isso que há algo errado, mas apenas que existe uma aceitação coletiva de significados que permitem a incorporação de ingredientes, saberes e fazeres às cozinhas (TURMO, 1999). E, se é verdade que a cozinha se constitui de significados, da distinção e qualificação de ingredientes e gostos, o resultado do que se transmite e se consome necessita de reconhecimento como bem intangível, levando também em conta que as cozinhas foram, ao longo do tempo, alvo de conservadorismo e extremismos.

Deve-se reconhecer que existem alterações que são justificadas tanto pelas condições do grupo no meio (como novos estilos de vida, mudanças climáticas e ambientais, novas estruturas econômicas e sociais, dentre outras), quanto por condições externas (como conquistas de territórios, migrações e imigrações, modificações genéticas, uso de novas tecnologias, expansão comercial, etc.). Infelizmente, e apesar da diversidade de ingredientes e cozinhas das regiões brasileiras, o país não dispõe de cozinha patrimonializada.

A ligação dos hábitos alimentares com a identidade cultural não se apresenta fixa e imutável, mas varia de acordo com o consumo do mercado global e adaptações localizadas. James (1994) destaca que, com isso, se pode confrontar estilos alimentares globais e locais e pessoais, por meio do que é percebido com o imaginário.

A resposta comercial que justifica esse entendimento, no mercado, é a presença de produtos com apelação de origem, como o uso de indicações geográficas em alimentos, bebidas, artesanato ou em qualquer produção peculiar de um lugar específico cuja tradição e qualidade são reconhecidas e aquecem a economia (COELHO-COSTA, 2014), de modo que a gastronomia e a atividade turística as percebam como catalizadores para gerar competitividade do destino.

\section{Cozinhas patrimoniais e turismo}

Conhecer culturas é uma das fortes motivações existentes na atividade turística (BURBRIDGE, 1993). Consequentemente, ir ao encontro dessa cultura pelo turismo faz o turista perceber valores culturais e admirar o patrimônio cultural de um lugar.

Por este motivo, a Comissão Europeia de Turismo, em 1954, já destacava que as paisagens, monumentos, cidades e costumes constituem o capital turístico; e, mais tarde, o documento conhecido como "Normas de Quito" (1967), tratando da relação do patrimônio com o turismo, explicaria o seguinte:

\footnotetext{
Os valores propriamente culturais não se desnaturalizam nem comprometem ao vincular-se com os interesses turísticos e, longe deles, a maior atração que conquistam os monumentos e a influência crescente de admiradores estrangeiros contribui para afirmar a consciência de sua importância e significações nacionais. Um monumento restaurado adequadamente ou um conjunto urbano posto em valor continue, não só uma lição viva de história, mas um legítimo motivo de dignidade nacional. No mais vasto marco das relações internacionais, esses testemunhos do passado estimulam os sentimentos de compreensão, harmonia e comunidade espiritual, ainda que povos que se mantem rivais em política... a Europa deve ao turismo direta ou indiretamente, a salvaguarda de uma grande parte de seu patrimônio cultural (NORMAS DE QUITO, 1967).
} 
A Unesco, com a ajuda da União Internacional de Organizações Oficiais de Turismo, depois de um exaustivo estudo chegou à aprovação de critérios que justificam a utilização do patrimônio em função do turismo, e, ainda, instituiu os benefícios econômicos que derivam desta política. Deste fato, dois extremos devem ser destacados: a influência turística determina a reavaliação de um monumento e assegura a rápida recuperação do capital investido para este fim; o desaparecimento da atividade turística, que se origina como consequência da apresentação adequada de um monumento, determinaria sua extinção.

Partindo do conceito de "recurso", a Organização Mundial do Turismo (OMT, 1998) define patrimônio turístico como conjunto de ativos tangíveis e intangíveis que são a matéria-prima que torna possível o desenvolvimento do turismo. A OMT destaca que há diferença entre produto, oferta e recurso - este último não seria válido por si mesmo, mas pela capacidade de transmissão para satisfazer as necessidades da demanda. Logo, o patrimônio turístico é o conjunto de bens materiais e imateriais que constitui a matéria prima para o desenvolvimento do turismo (SCHLÜTER, 2006, p. 32-33).

Prats (1997, p. 43) destaca que, no turismo, os recursos patrimoniais são percebidos pelos empreendedores da atividade como recursos gratuitos, que conferem ao destino distinção e respeitabilidade, e não estão sujeitos à sazonalidade como outros recursos turísticos. $\mathrm{O}$ autor ainda classifica o patrimônio como recurso turístico levando em consideração as seguintes observações:

- Produto turístico com capacidade de com a oferta hoteleira um motivo de compra independente;

- Produto turístico integrado que se combina com outros atrativos;

- Produto turístico com valor acrescentado nos destinos que não têm o patrimônio como motivo principal.

A gastronomia tem destaque relevante para o turismo, sobretudo para o segmento cultural, em que se percebe a necessidade emergencial de aprofundar conhecimento sobre o patrimônio gastronômico regional "considerado como um dos pilares indispensáveis sobre os que deveria fundar-se em grande parte o desenvolvimento do turismo cultural” (ALVAREZ, 2002, p. 17).

Indiscutivelmente, as cozinhas patrimoniais podem se configurar como recurso importante para atividade turística, podendo ser bastante exploradas nos segmentos do turismo, cultura, agroturismo, gastronômico, enogastronômico, rural, dentre outros. Em qualquer um destes segmentos, as cozinhas patrimoniais tornam-se atrativo turístico. E, assim, utilizando a cultura como diferencial, que se reinterpreta e se reinventa, tem-se nelas a função de obter clientela parcial ou efetiva (TALAVERA, 2003).

As comidas típicas permitem a aproximação dos turistas com a cultura alimentar do lugar visitado. Produções alimentares patrimonializadas têm maior êxito como atrativo, pois tratam de produtos locais que exalam a identidade e cultura do lugar - como diria La Cecla e DiNatale (1995, p. 85), a cozinha patrimonializada é um dos hábitos mais acessíveis de uma cultura.

Para Ascanio (2000), a gastronomia enquanto patrimônio local vem sendo incorporada aos novos produtos turísticos, principalmente em segmentos e nichos de mercado, que permitem incorporar os atores do lugar na elaboração de produtos para auxiliar o desenvolvimento sustentável da atividade. Além disso, como explica Bernier (2003), é possível distinguir o tipo de turista entre o que come porque viaja, e o que viaja para comer. O primeiro não manifesta interesse especial pela gastronomia local, mas deseja que a mesma se adapte às suas necessidades e preferências no destino visitado. Neste caso, uma atenção adequada destinada a turistas que se sentem satisfeitos com a viagem e estadia é um fator importante. Assim, é possível afirmar que um turista mal comido é um turista insatisfeito.

Algumas vezes, a falta de interesse em experimentar preparações gastronômicas locais deve-se ao medo de sofrer qualquer desequilíbrio que estrague a viagem (COHEN \& AVIELI, 2004). Outro problema relevante ao estranhamento causado na apresentação de alimentos durante a atividade turística é a falta de informação sobre as produções e os hábitos gastronômicos do lugar visitado, que leva o turista a se resguardar e, até a gerar má interpretação e julgamentos errôneos sobre pratos exóticos, o que acaba impedindo o consumo de alimentos. 
Dossiê

Eco (1983), em O nome da Rosa, destaca o conflito presenciado pelo personagem Adso, a partir de diferenças culturais em relação à colheita de trufas:

Vi Severino que reunia os porqueiros e alguns de seus animais, com alegria. Disse-me que iam
pelas faldas do monte, e no vale, procurar trufas. Eu ainda não conhecia aquele fruto prelibado
da mata que crescia naquela península, e parecia típico das terras beneditinas, quer em Norcia
- preto - quer naquelas terras - mais claro e perfumado. Severino explicou-me o que era, e o
quanto a trufa era gostosa, preparada nos modos mais variados. E disse-me que era dificilima
de achar, porque se escondia debaixo da terra, mais escondida que um fungo, e os únicos mais
capazes de escavá-lo seguindo o olfato eram os porcos. Exceto que, quando achavam, queriam
devorá-la, e era preciso afastá-los e intervir para desenterrá-lo. Soube mais adiante que muitos
cavalheiros não desdenhavam dedicar-se àquela caça, seguindo os porcos como se fossem
sabujos nobilíssimos, e seguidos por sua vez pelos seus servos com as enxadas. Recordo aliás
que anos mais tarde um senhor da minha terra, sabendo que eu conhecia a Itália, me perguntou
se nunca tinha visto lá embaixo os senhores irem pastorear os porcos, e eu ri compreendendo
que, ao contrário, estavam procurando trufas. Mas quando eu lhe disse que queriam encon-
trar "tru-fa" embaixo da terra para depois comê-la, ele entendeu que eu estava dizendo que
procuravam "der Teufel", ou seja, o diabo, e persignou-se devotamente fitando-me assustado.
Depois o equívoco se desfez e ambos rimos. Tal é a magia dos falares humanos, que por huma-
no acordo significam frequentemente, com sons iguais, coisas diferentes. (ECO, 1983, p. 331).

A citação destaca que, pelo não conhecimento da cultura do outro, o espectador é induzido a julgamentos errôneos: inicialmente, a acreditar que os porcos eram os animais de caça nobres italianos e, na sequência, a mal traduzir o termo "tru-fa", dando ao nome um significado mefistofélico - fato perigoso, considerando que isto teria ocorrido na Idade Média, quando errar em interpretações poderia levar alguém a ser queimado em uma fogueira. Partindo desse episódio, ressalta-se a importância e o cuidado com as traduções e informações passadas aos interlocutores, principalmente quando estes desconhecem hábitos locais. Erros semelhantes podem ser encontrados em guias turísticos, em que a falta de conhecimento e traduções erradas fazem com que tragam informações equivocadas, que não condizem com o que, de fato, se queria apresentar.

No entanto, este exotismo que pode afastar alguns turistas, é o mesmo que tem potencial de atração para outros. A importância da cultura e dos regionalismos tornam-se os elementos catalizadores neste poder de atrair visitantes que têm a gastronomia, as cozinhas e o terroir.

O uso do terroir e dos bens especiais agroalimentares (BEAs) é amplamente difundido na área da gastronomia, onde os renomados chefs de cozinha se utilizam de produtos com indicações geográficas (IGs) para oferecer aos comensais pratos que refletem a identidade de um povo e a explosão de criatividade no preparo dos pratos. Na gastronomia os produtos com IG e/ou os BEAs são considerados como luxo gastronômico. (COELHO-COSTA, 2014, p. 38).

Entretanto, o terroir brasileiro precisa ser conhecido e, junto com as cozinhas regionais brasileiras, ter maior visibilidade e ser melhor explorado no turismo. Para tanto, devem existir segmentos como o turismo cultural, gastronômico, enoturismo, rural e agroturismo, em que rotas e produtos turísticos direcionados e com foco na gastronomia configuram-se como vitrines para apresentar aos visitantes o que as cozinhas locais têm de melhor. A realização de festivais e eventos gastronômicos é outra maneira do turismo aproveitar a cultura gastronômica e suas produções para atrair turistas, sobretudo para enfrentar a sazonalidade.

\section{Considerações finais}

As cozinhas patrimoniais representam as artesanías alimentares das sociedades. Logo, é imprescindível a patrimonialização das cozinhas e os registros de saberes e fazeres, principalmente quando se constata que os mesmos correm o risco de desaparecer, sendo necessário que sejam reconhecidos, resgatados e repassados para as pessoas, sejam elas turistas ou não. 
Na medida em que uma cozinha se configura enquanto elemento cultural reconhecido como patrimônio seu uso transcende a nutrição e passa a ter funções políticas, socioeconômicas e culturais que representam interesses e destacam a identidade e o território a qual a cozinha pertence.

Apesar de o Brasil dispor de grande diversidade na alimentação e de cozinhas diferenciadas em cada região, ainda não se tem cozinhas patrimonializadas. No máximo o que se encontram são alguns saberes e fazeres, ligados à gastronomia, tombados pelo Iphan. São eles: o Ofício das Paneleiras de Goiabeiras; o Ofício das Baianas do Acarajé; o Modo Artesanal de Fazer Queijo de Minas nas Regiões do Serro, da Serra da Canastra e do Salitre em Minas Gerais; e a Produção Tradicional e Práticas Socioculturais Associadas à Cajuína no Piauí.

Cada cozinha tem sua singularidade. Logo, se constata a existência de cozinhas diferentes que se reproduzem e se reinterpretam ao longo do tempo. No entanto, a cozinha enquanto patrimônio deve explorar todas as sensorialidades no ato de comer para despertar imagens que permitam a ligação afetiva do comensal com as produções alimentares, valores e simbologias.

Conclui-se, portanto, que as cozinhas podem sim ser patrimonializadas, sobretudo quando se consideram as culinárias como materialização da cultura alimentar de uma sociedade, e que elas manifestam transmissão, valorização e consumo de saberes e fazeres de grupos e identidades distintas.

O uso das cozinhas patrimoniais na atividade turística, além de agregar valor ao destino turístico, oportuniza desenvolvimento de rotas, produtos e atrativos turísticos que se tornam melhor explorados a partir da segmentação do mercado turístico, especialmente com atividades ligadas ao turismo cultural, gastronômico, enogastronômico, rural e agroturismo. Partindo de representações e aspectos simbólicos, as cozinhas patrimoniais proporcionam interação entre turistas, residentes e a cultura gastronômica de um lugar.

A ação de patrimonializar cozinhas e tê-las em uso na atividade turística implica diretamente em compreender a necessidade emergente de resgatá-las, valorizá-las e reafirmá-las como parte da identidade de uma sociedade. O desenvolvimento local e o desenvolvimento à escala humana são duas vertentes que podem ocorrer em destinos turísticos que resolvem trabalhar cozinhas patrimoniais como atrativo/produto turístico. O desenvolvimento local, que oportuniza o crescimento do lugar, o desenvolvimento econômico e a conservação ambiental, pressupõe capital e lucro e gera modificações conscientes da realidade do lugar, inclusive na realidade gastronômica, com articulações políticas integradas por atores do poder público, iniciativa privada e residentes, envolvendo diretamente setores ligados à gastronomia em prol do desenvolvimento do lugar. Enquanto o desenvolvimento à escala humana, que se sustenta em atender as necessidades básicas das pessoas respeitando valores, culturas, costumes e diferenças; oportunizaria a valorização de saberes e fazeres de uma sociedade, que transformaria os mesmos em produtos turísticos, gastronômicos ou não, com carga identitária que estimula a percepção de residentes quanto à sua importância para a construção do lugar e de tudo que nele é produzido. Neste último caso, saberes e fazeres preservados são fundamentais para a sobrevivência de receituários e modos de preparar alimentos e bebidas típicos - além do reconhecimento das pessoas com seus conhecimentos paras estes fins.

Sugere-se que a exploração das cozinhas patrimoniais pelo turismo tenha destaque nos planejamentos de destinos turísticos, pelo fato de estarem impregnadas de cultura e identidade do lugar, além de nutrirem os visitantes de comida, imaginário e simbologia.

Criar roteiros especializados, eventos gastronômicos e incentivar o turismo em mercados e feiras, é uma forma de dar visibilidade ao patrimônio alimentar e fazer com que o turista tenha contato direto com o patrimônio gastronômico. No entanto, ressalta-se que mercados e feira locais, em muitos destinos, apesar de disponibilizarem contato com produtos locais e culinária típica, não estão estruturados para a visitação turística e, assim, precisar-se-ia repensar os usos destes espaços e adequá-los para esta finalidade. Poderão governos e gestores locais e regionais de turismo e do setor gastronômico, juntamente com as instituições de ensino superior e investigação, assumir estes desafios? Acredita-se que sim, desde que haja integração e pensamento focado na melhoria da atividade. 
Dossiê

\section{Referências}

ÁLVAREZ, Marcelo. El patrimonio ya no es lo que era: los recursos alimentarios entre la diferencia cultural y la desigualdad social. In: ALVAREZ, M.; MEDINA, F.X. Identidades en el platô. Barcelona: Icaria, 2008. p. 25-44.

. La cocina como patrimonio (in) tangible. In: COMISIÓN PARA LA PRESERVACIÓN DEL PATRI-

MONIO HISTÓRICO CULTURAL DE LA CIUDAD DE BUENOS AIRES. La cocina como patrimonio (in) tangible.

Buenos Aires: Imprenta del Gobierno de la Ciudad de Buenos Aires, 2002. p. 11-25. (Temas de Patrimonio Cultural 8).

ANTONINI, Bianca Oliveira. A gastronomia típica da ilha de Santa Catarina: um elemento d e importância para o turismo cultural. 2003. Dissertação (Mestrado em Turismo e Hotelaria) - Universidade do Vale do Itajaí, Itajaí. 2003.

APPADURAI, Arjun. Gastro-politics in Hindu South Asia. American Ethnologist, Malden, v. 8, n. 3, p. 494-511, 1981.

ARANTES, Antonio Augusto. Produžindo o passado: estratégias de construção do patrimônio cultural. São Paulo: Brasiliense, 1984.

ASCANIO, Alfredo. Turismo: Vieja y nueva gastronomía. Una estrategia para desarrollar rutas novedosas. Ruta Revista Universitària de Trabells Acadèmics. Madrid: Ediciones Marañon, p. 105-113, 2000.

BARCELÓ, Q. R. Turismo y patrimônio alimentario: un análisis de conceptos. In: ARIAS, David Lagunas (Coord.). Antropología y turismo. Claves culturales y disciplinares. México: Universidad Autónoma del Estado de Hidalgo-Plaza y Valdés Editores, 2007. p. 209-226.

BARROS, Cristina. Prólogo, en Anónimo. El cocinero mexicano. Tomo i. Conaculta: México, 2000.

Los libros de la cocina mexicana. Conaculta: México, 2008.

BERNIER, Enrique José Torres. El turismo residenciado y sus efectos en los destinos turísticos. Estudios Turísticos, n. 155, p. 45-70, 2003.

BESSIÈRE, Jacinthe; TIBÈRE, Laurence. Innovation et patrimonialisation alimentaire: quels rapports à la tradition? 2010. Disponível em: < http://www.lemangeur-ocha.com/fileadmin/images/sciences humaines/Texte exclusif BESSIE$\underline{\mathrm{RE}}$ et TIBERE innovation et patrimonialisation.pdf.> Acesso em: 17 jun. 2015.

BOURDIEU, P. La distinción. Criterios y bases sociales del gusto. Madrid: Taurus, 1988.

BURBRIDGE, Horacio. El turismo cultural. Política Turística Argentina. Buenos Aires: Ladevi Ediciones, 1999.

CARVALHO, Edwin. Ortiz propõe debate sobre representações da cultura brasileira e da identidade nacional. Revista Internacional de Folkcomunicação, Ponta Grossa, v. 11, n. 24, p. 122-133, 2014. Disponível em: < http://www.revistas.uepg. br/index.php/folkcom/article/view/1652/1168>. Acesso em: 07 set. 2015.

COELHO-COSTA, Ewerton Reubens. As Indicações Geográficas (IGs) como elementos fortalecedores para a atividade turística. Turismo: Estudos \& Práticas, Mossoró, vol. 3, n. 1, p. 25-50, jan./jun. 2014. Disponível em: < http://periodicos.uern.br/index.php/turismo/article/viewFile/1073/588>. Acesso em: 20 jun. 2015.

COHEN, Erik; AVIELI, Nir. Food in tourism: Attraction and impediment. Annals of tourism Research, Wisconsin, EUA, v. 31, n. 4, p. 755-778, 2004. Disponível em: < http://www.sciencedirect.com/science/article/pii/

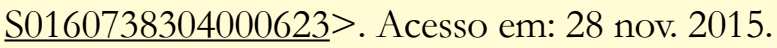

CORNER, Dolores Martin Rodriguez. La gastronomia española como patrimônio cultural. In: GÂNDARA, Jose Manoel G.; SCHLÜTER, Regina G. (Orgs.). Gastronomia y Turismo. Argentina: CIET, 2003.

DAMATTA, Roberto. La cultura de la mesa en Brasil. El Correo Unesco, p. 22-23 maio 1987. Disponível em: $<\underline{\text { http: } / /}$ unesdoc.unesco.org/images/0007/000731/073178so.pdf>. Acesso em: 28 nov. 2015.

GIORGI, Victor de Vargas. Adentrando o “espaço social alimentar”': sociologias da alimentação, por Jean-Pierre Poulain. Demetra: Alimentação, Nutrição \& Saúde, Rio de Janeiro, v. 10, n. 3, p. 729-738, 2015. Disponível em: < http:// www.e-publicacoes.uerj.br/ojs/index.php/demetra/article/view/15858/13762\#.VhW4cPlViko > . Acesso em: 07 set. 2015. 
ECO, Umberto. O nome da Rosa. Rio de Janeiro: Nova Fronteira. 1983.

ESPEITX, Elena. Patrimonio alimentario y turismo: una relación singular. Pasos: revista de turismo y patrimonio cultural, Universidade de La Laguna, Espanha, v. 2, n. 2, p. 193-213, 2004. Disponível em: < http://www.pasosonline.org/Publicados/2204/PS040204.pdf>. Acesso em: 20 jun. 2015.

FARB, Peter; ARMELAGOS, George J.; DESMOND, William. Anthropologie des coutumes alimentaires. Denoël: Paris, 1985.

FISCHLER, Claude. Presentation. Communications, Seuil, Paris, n. 31, p. 1-3, 1979.

FREYRE, Gilberto. Manifesto Regionalista. Recife: Instituto Joaquim Nabuco de Pesquisas Sociais, 1967.

JAMES, Allison. Cuisiner les livres. Identités globales ou locales dans les cultures alimentaires? Anthropologie et sociétés, Département d’Anthropologie de l’Université Laval, Québec, Canada, v. 18, n. 3, p. 39-56, 1994.

LA CECLA, Franco; DI NATALE, I. Faux contact. In: BESSIS, Sophie. Mille et une bouches. Cuisines et identités culturelles. Paris: Autrement, 1995. p. 82-88. (Coll. Mutations/Mangeurs).

LIMA, Cláudia. Para uma Antropologia da Alimentação Brasileira. 2005, p. 1-6. Disponível em: < $\underline{\text { http://www.claudialima. }}$ com.br/pdf/ANTROPOLOGIA DA ALIMENTACAO BRASILEIRA.pdf >. Acesso em: 20 jun. 2015.

LODY, Raul Giovanni da Motta. Brasil bom de boca: temas da antropologia da alimentação. São Paulo: Senac, 2008.

MANTECÓN, Angel. R. Presentación. Revista Alteridades, México, ano 8, n. 16, p. 3-9, jul./dez. 1998.

MONTANARI, Massimo. Comida como cultura. São Paulo: Senac, 2008.

NORA, Pierre. Les Lieux de Mémoire. I La Republique. Paris: Gallimard, 1984.

NORMAS DE QUITO. Informe Final de la reunión sobre Conservación y Utilización de Monumentos y Lugares de Interés Histórico y Artístico. 1967. Disponível em: < http://www.sedpgym.es/descargas/doc-patrimonio/1967-normas-de-quito.pdf>.

Acesso em: 12 jun. 2015.

NARAYAN, Uma. Eating cultures: incorporation, identity and Indian food. Social Identities, Berkeley, v. 1, n. 1, p. 63-86, abr. 1995.

ORGANIZACIÓN MUNDIAL DEL TURISMO. Introducción al turismo. Madrid: OMT, 1998.

PÉREZ SAN VICENTE, G. Reflexiones y una teoría sobre la gastronomía mexicana, en Patrimonio cultural y turismo. Cuadernos del Congreso sobre Patrimonio Gastronómico y Turismo Cultural en América Latina y el Caribe. Memorias. Tomo i. México: Conaculta, 2002.

PILCHER, Jeffrey. ¡Vivan los tamales! La comida y la construcción de la identidade mexicana. México: Ediciones de la Reina Roja; Conaculta, 2001.

PRATS, L. Antropología y patrimonio. Barcelona: Ariel, 1997.

QUINTERO MORÓN, Victoria. El patrimonio intangible como instrumento para la diversidad cultural: ¿una alternativa posible? Sevilla: Instituto Andaluz del Patrimonio Histórico, Consejería de Cultura da Espanha, v. 17, p. 69-83, 2005.

SCHLÜTER, Regina G. Turismo y patrimonio gastronómico: una perspectiva. Buenos Aires: Centro de Investigaciones y Estudios Turísticos, 2006.

TALAVERA, Agustín Santana. Mirando culturas: la antropología del turismo. In: Sociología del turismo. La Rioja, Espanha: Ariel, 2003. p. 103-126.

TURMO, Isabel González. Alimentación y patrimonio: Ayer y hoy. In: CONGRESO DE ANTROPOLOGÍA, 8, 1999, Santiago de Compostela. Anais... Santiago de Compostela: FAAEE, 1999. p. 141-150.

UNESCO (Organização das Nações Unidas para a Educação, Ciência e Cultura). Convenção para a salvaguarda do patrimônio cultural imaterial. Paris, 17 out. 2003. Disponível em: < http://www.unesco.org/culture/ich/doc/src/00009-PT-Portugal-PDF.pdf >. Acesso em: 12 jun. 2015. 